\title{
TEMPERATURE DEPENDENCE OF KINETIC PARAMETERS RELATED TO OXYGEN ELECTROREDUCTION IN ACID SOLUTIONS ON PLATINUM ELECTRODES
}

\author{
C. F. Zinola, A. M. Castro Luna and A. J. Arvia \\ Instituto de Investigaciones Fisicoquimicas Teoricas y Aplicadas (INIFTA), Universidad Nacional de La \\ Plata, Sucursal 4, Casilla de Correo 16, (1900) La Plata, Argentina
}

(Received S January 1994)

\begin{abstract}
The oxygen electroreduction reaction (OERR) kinetics at (111)- and (100)-type Pt electrodes has been studied in aqueous $1.0 \mathrm{M} \mathrm{H}_{2} \mathrm{SO}_{4}$ solutions in the $8-62^{\circ} \mathrm{C}$ range. On both $\mathrm{Pt}$ electrodes and at all temperatures, two Tafel regions have been observed. The Tafel slope in the low current density range is $-0.053 \pm 0.005 \mathrm{~V}_{\text {decade }}{ }^{-1}$, irrespective of temperature and the surface texture of the electrode. For (111)-type $\mathbf{P t}$, the Tafel slope in the high current density range increases with temperature, approaching the $-2.303(2 R T / F)$ ratio, whereas for $(100)$-type $\mathrm{Pt}$, it reaches a temperature-independent value equal to $-0.165 \pm 0.003 \mathrm{~V} \mathrm{decade}^{-1}$. Temperature dependences of OERR Tafel slopes on both types of Pt electrodes offer the possibility of further insights into the mechanism of the reaction, through the interpretation of both the adsorption enthalpy and entropy of intermediates produced along the OERR. Compensation effects, involving activation enthalpy and entropy variations with the applied potential, are also considered to account for experimental data.
\end{abstract}

Key words: oxygen, electroreduction, platinum, temperature, kinetics parameters.

\section{INTRODUCTION}

It is well known that the efficiency of Pt-acid electrolyte fuel cells is limited by the OERR overpotential[1-3]. The rate of this reaction at oxide-free Pt surfaces, which is the first single electron transfer to molecular $\mathrm{O}_{2}[4,5]$, appears to be determined by the adsorption of products formed at the rate determining step ( $r d s$ ). The OERR stationary kinetics on smooth polycrystalline $(\mathrm{PC})$ and facetted Pt electrodes fit Tafel lines with two distinct Tafel regions, namely, a low current density region, $\mathrm{LCD}$, with a slope $\left(b_{\mathrm{T}}\right)_{\mathrm{LCD}} \cong-0.060 \mathrm{~V}_{\text {decade }}{ }^{-1}$ in both acid and alkaline solutions, and a high current density region, $\mathrm{HCD}$, with Tafel slopes, $\left(b_{\mathrm{T}}\right)_{\mathrm{HCD}}$, ranging from -0.120 to $-0.165 \mathrm{~V} \mathrm{decade}^{-1}$, depending on both the electrode topology and the degree of surface coverage by adsorbable anions and OERR intermediates $[6,7]$.

The influence of temperature on the OERR kinetics deserves further work, because unlike simple processes, the interpretation of the electrochemical activation parameters is still rather unsatisfactory.

Generally, the adsorption of intermediates in electrocatalytic reactions influences the rate of the electron transfer step. For the OERR, Huang et al.[8] and Appleby[9] have found no significant changes of $\left(b_{\mathrm{T}}\right)_{\mathrm{HCD}}$ in concentrated aqueous $\mathrm{H}_{3} \mathrm{PO}_{4}$ in the 25 $250^{\circ} \mathrm{C}$ range. It has been recently found, however, that these kinetic results are influenced by the presence of a Pt anodic film on the electrode, formed at high potentials, and by the $\mathrm{Pt}$ surface restructuring upon potential cycling[10]. Conversely, Damjanovic and co-workers[11-13] have reported values of $\left(b_{\mathrm{T}}\right)_{\mathrm{HCD}}$ increasing with temperature in diluted aqueous $\mathrm{HClO}_{4}$ and $\mathrm{H}_{2} \mathrm{SO}_{4}$ below $70^{\circ} \mathrm{C}$, as predicted by classical theories of electron transfer reactions at electrified interfaces. Reports by Conway and McKinnon on the hydrogen evolution reaction (HER) in ethanolic and methanolic acid solutions [14], and by Conway et al. on the bromine evolution reaction (BER) on graphite[15], have shown that the temperature dependence of $\left(b_{\mathrm{T}}\right)_{\mathrm{HCD}}$ is related to the nature of the electrode and the operating temperature range $[14,16,17]$. It is clear that, despite the number of works about OERR on PC Pt and well-defined $\mathrm{Pt}$ electrodes[17-21], there are some fundamental kinetic aspects which are still far from being well established.

This work deals with the kinetics of the OERR in diluted acid media, at different temperatures, followed through the rotating disc electrode (rde) technique on two differently facetted Pt surfaces. New results offer the possibility of obtaining thermodynamic data related to the activated process involved in the OERR, and of advancing an interpretation about the temperature dependence of Tafel slopes, under several operating conditions.

\section{EXPERIMENTAL}

Pt discs (99.999\% purity, $3 \mathrm{~mm}$ dia.) were mirror polished using successive alumina pastes down to 
$0.5 \mu \mathrm{m}$ grit, subsequently immersed in $1: 1$ aqueous nitric sulfuric acid mixture for $5 \mathrm{~min}$, and rinsed with Millipore-MilliQ water. Electrochemical kinetic runs were made in aqueous $\mathrm{O}_{2}$-free and $\mathrm{O}_{2}$-saturated ( $\left.P_{\mathrm{O}_{2}}=1 \mathrm{~atm}\right) 1.0 \mathrm{M}$ aqueous $\mathrm{H}_{2} \mathrm{SO}_{4}$, prepared from $98 \%$ sulfuric acid A.R. and Millipore-MilliQ water, in the 8-62 $\pm 0.1^{\circ} \mathrm{C}$ range. Facetted (111)- and (100)type $\mathrm{Pt}$ disc working electrodes were prepared using the repetitive square wave potential routine, as described elsewhere[22].

The working electrode real surface area $\left(A_{\mathrm{D}}\right)$ was estimated from the $\mathrm{H}$-adatom charge density reading from voltammograms run at $0.1 \mathrm{Vs}^{-1}$, after the double layer correction, considering as a reference the $\mathrm{H}$-adatom monolayer charge density at each $\mathrm{Pt}$ single crystal electrode surface[23]. A $10 \mathrm{~cm}^{2}$ geometric area platinized-Pt counter electrode facing the working electrode, and a reversible hydrogen electrode (rhe), connected to the rest of the cell through a capillary tip, were employed. A conventional two compartment cell of $c a$. $350 \mathrm{~cm}^{3}$ capacity was used, and the arm of the reference electrode compartment was separated from the working cell by means of a Teflon stopcock. The reference electrode compartment was held at $25^{\circ} \mathrm{C}$ to perform the experiments at constant potential (non-isothermal conditions) $[24,25]$. Potentials in the text are referred to the rhe scale. Oxygen ( $99.99 \%$ purity) and nitrogen $(99.998 \%$ purity) were treated as indicated elsewhere[26], and then bubbled through the solution until saturation was reached.

The kinetics of the OERR at different temperatures was followed by using the rde technique. Prior to each run, disc electrodes were cleaned employing a potential routine already described in the literature[7]. Stationary polarization curves were obtained under potentiostatic conditions, by holding the disc potential $\left(E_{\mathrm{D}}\right)$ at a preset value in the $0.05 \mathrm{~V} \leqslant E_{\mathrm{D}} \leqslant E_{\text {rest }}$ range, $E_{\text {rest }}$ being the open circuit potential of $\mathrm{Pt}$ in the $\mathrm{O}_{2}$-saturated $\left(\mathrm{P}_{\mathrm{O}_{2}}=1 \mathrm{~atm}\right)$ acid solution, and by reading the stationary current after no less than a 4 min stability. Polarization curves were independent of whether $E_{\mathrm{D}}$ was changed upwards or downwards within the $0.05 \mathrm{~V}$ to $E_{\text {rest }}$ potential range. The stationary polarization curves were displayed as $E_{\mathrm{D}}$ vs. $\log j$ plots (Tafel plots), where $j$ is the cathodic current density at the disc electrode referred to $A_{\mathrm{D}}$. Tafel plots were properly corrected for mass transport contribution, assuming a first order kinetics with respect to $\mathrm{O}_{2}[27]$.

\section{RESULTS AND INTERPRETATION}

\subsection{Electrochemical behaviour of $\mathrm{Pt}$ electrodes}

Cyclic voltammetry was used to test both the stability of facetted $\mathrm{Pt}$ electrodes and the absence of impurities in the solution, which could interfere with the kinetics of the OERR under different experimental conditions[28].

Cyclic voltammograms of (100)- and (111)-type $\mathrm{Pt}$ electrodes were run at $0.10 \mathrm{~V} \mathrm{~s}^{-1}$, between 0.5 and $1.5 \mathrm{~V}$, in $\mathrm{O}_{2}$-free $1.0 \mathrm{M}$ aqueous $\mathrm{H}_{2} \mathrm{SO}_{4}$, in the $8-62^{\circ} \mathrm{C}$ range. The voltammetric response of (111)type $\mathrm{Pt}$ is similar to that previously reported for a $\mathrm{Pt}$ surface with a large fraction of reaction sites for weakly adsorbed $\mathrm{H}$-atoms, whereas for the (100)type $\mathrm{Pt}$ it approaches that reported for Pt surfaces with a large fraction of reacting sites for strongly adsorbed $\mathrm{H}$-atoms[7]. Cyclic voltammograms for both Pt facetted surfaces showed no appreciable changes in the $\mathrm{H}$ - and $\mathrm{O}$-adatom contours after $1 \mathrm{~h}$ temperature holdings in the $8-62^{\circ} \mathrm{C}$ range. This was taken as an indication that $\mathrm{Pt}$ electrodes were stable during the kinetic experiments.

\subsection{Stationary polarization curves}

Tafel plots for the OERR on (111)- and (100)-type $\mathrm{Pt}$ in $\mathrm{O}_{2}$-saturated $1.0 \mathrm{M}$ aqueous $\mathrm{H}_{2} \mathrm{SO}_{4}$, at different temperatures (Fig. 1), show, in all cases, a low current density and a high current density linear region. The value of $\left(b_{\mathrm{T}}\right)_{\mathrm{LCD}}$ is slightly lower than the $-2.3(R T / F)$ ratio, and tends to decrease as the temperature is raised, irrespective of the electrode texture.

Otherwise, $\left(b_{\mathrm{T}}\right)_{\mathrm{HCD}}$ increases with temperature and fits the $-2.3(2 R T / F)$ ratio for (111)-type $\mathrm{Pt}$, in agreement with the results reported by Sepa et al. for

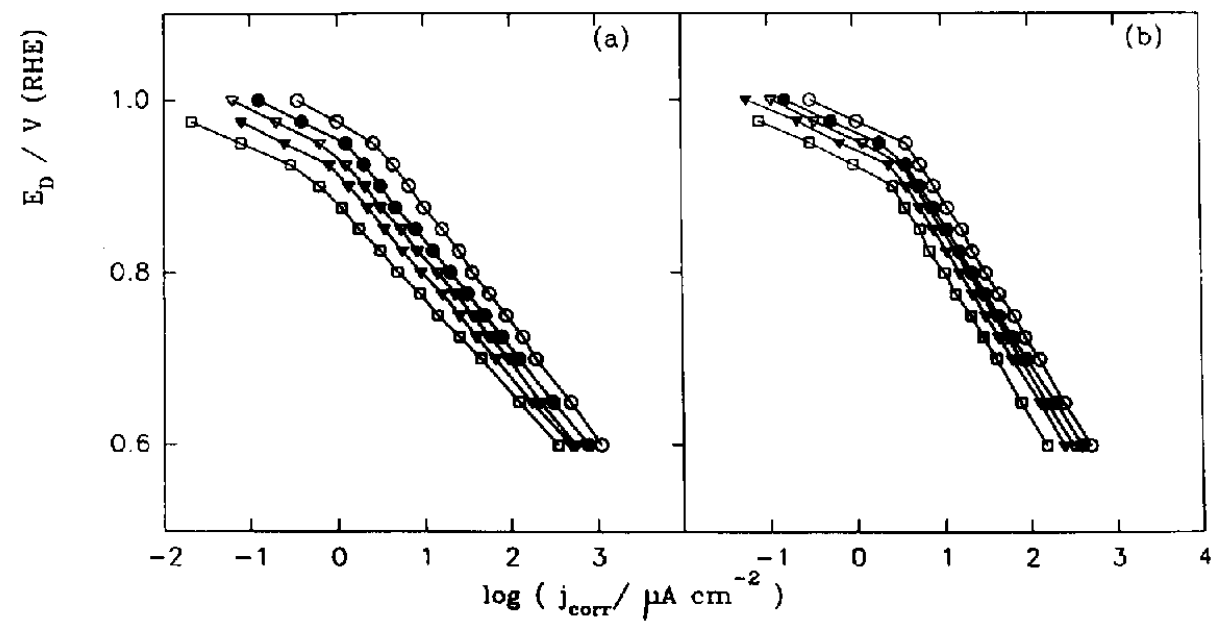

Fig. 1. Tafel lines for OERR in $\mathrm{O}_{2}$-saturated $1.0 \mathrm{M}$ aqueous $\mathrm{H}_{2} \mathrm{SO}_{4}$. (a) (111)-type $\mathrm{Pt}$; (b) (100)-type $\mathrm{Pt}$ at different temperatures, $(\square) 8^{\circ} \mathrm{C},(\nabla) 20^{\circ} \mathrm{C},(\nabla) 30^{\circ} \mathrm{C},(\mathrm{O}) 40^{\circ} \mathrm{C},(\mathrm{O}) 62^{\circ} \mathrm{C}$. 
Table 1. OERR kinetic parameters for (111)-type and (100)-type Pt electrodes in $\mathrm{O}_{2}$-saturated aqueous $1.0 \mathrm{M} \mathrm{H}_{2} \mathrm{SO}_{4}$ at $8,20,30,40$ and $62^{\circ} \mathrm{C}$

\begin{tabular}{|c|c|c|c|c|}
\hline $\begin{array}{l}T \\
{ }^{\circ} \mathrm{C}\end{array}$ & $\begin{array}{l}\left(b_{\mathrm{T}}\right)_{\mathrm{HCD}} \\
\mathrm{V} \mathrm{decade}^{-1}\end{array}$ & $\begin{array}{l}\left(j_{0}\right)_{\mathrm{HCD}} \\
\mathrm{Acm}^{-2}\end{array}$ & $\begin{array}{c}\left(b_{\mathrm{T}}\right)_{\mathrm{LCD}} \\
\mathrm{V} \text { decade } \\
\end{array}$ & $\begin{array}{r}\left(j_{0}\right)_{\mathrm{LCD}} \\
\mathrm{A} \mathrm{cm}^{-2} \\
\end{array}$ \\
\hline \multicolumn{5}{|c|}{ (111)-type Pt } \\
\hline $\begin{array}{r}8.0 \\
20.0 \\
30.0 \\
40.0 \\
62.0 \\
\end{array}$ & $\begin{array}{l}0.111 \pm 0.003 \\
0.117 \pm 0.003 \\
0.119 \pm 0.002 \\
0.124 \pm 0.002 \\
0.135 \pm 0.004\end{array}$ & $\begin{array}{l}(5.6 \pm 0.2) 10^{-10} \\
(2.0 \pm 0.2) 10^{-9} \\
(3.9 \pm 0.2) 10^{-9} \\
(7.5 \pm 0.2) 10^{-9} \\
(2.3 \pm 0.2) 10^{-8} \\
\end{array}$ & $\begin{array}{l}0.055 \pm 0.005 \\
0.053 \pm 0.005 \\
0.052 \pm 0.005 \\
0.053 \pm 0.005 \\
0.050 \pm 0.005\end{array}$ & $\begin{array}{l}(3.1 \pm 0.3) 10^{-13} \\
(7.1 \pm 0.3) 10^{-13} \\
(1.0 \pm 0.3) 10^{-12} \\
(3.2 \pm 0.3) 10^{-12} \\
(1.7 \pm 0.3) 10^{-11}\end{array}$ \\
\hline \multicolumn{5}{|c|}{ (100)-type Pt } \\
\hline $\begin{array}{r}8.0 \\
20.0 \\
30.0 \\
40.0 \\
62.0\end{array}$ & $\begin{array}{l}0.166 \pm 0.004 \\
0.165 \pm 0.004 \\
0.164 \pm 0.004 \\
0.163 \pm 0.004 \\
0.162 \pm 0.004\end{array}$ & $\begin{array}{l}(3.9 \pm 0.2) 10^{-8} \\
(4.3 \pm 0.2) 10^{-8} \\
(5.0 \pm 0.2) 10^{-8} \\
(5.7 \pm 0.2) 10^{-8} \\
(7.6 \pm 0.2) 10^{-8}\end{array}$ & $\begin{array}{l}0.055 \pm 0.005 \\
0.057 \pm 0.005 \\
0.053 \pm 0.005 \\
0.052 \pm 0.005 \\
0.051 \pm 0.005\end{array}$ & $\begin{array}{l}(1.1 \pm 0.3) 10^{-13} \\
(5.0 \pm 0.3) 10^{-13} \\
(1.0 \pm 0.3) 10^{-12} \\
(2.5 \pm 0.3) 10^{-12} \\
(1.2 \pm 0.3) 10^{-11}\end{array}$ \\
\hline
\end{tabular}

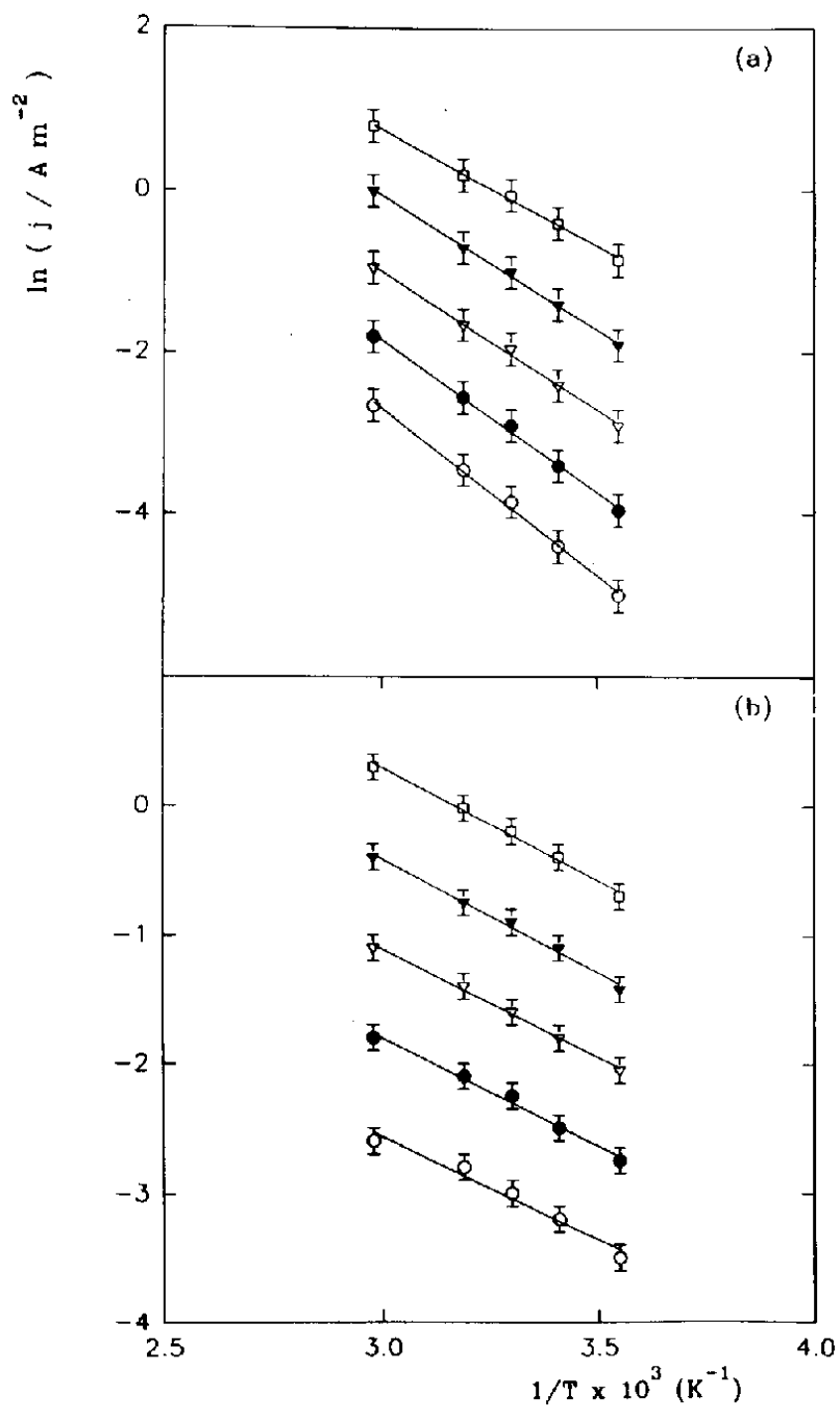

Fig. 2. Arrhenius plots for the OERR in $\mathrm{O}_{2}$-saturated $1.0 \mathrm{M}$ aqueous $\mathrm{H}_{2} \mathrm{SO}_{4}$. (a) (111)-type $\mathrm{Pt}$; (b) (100)type $\mathrm{Pt}$ for different $E_{\mathrm{D}}$ values, $(O) 0.90 \mathrm{~V},(\bigcirc) 0.85 \mathrm{~V},(\nabla) 0.80 \mathrm{~V},(\mathrm{~V}) 0.75 \mathrm{~V},(\square) 0.70 \mathrm{~V}$. 


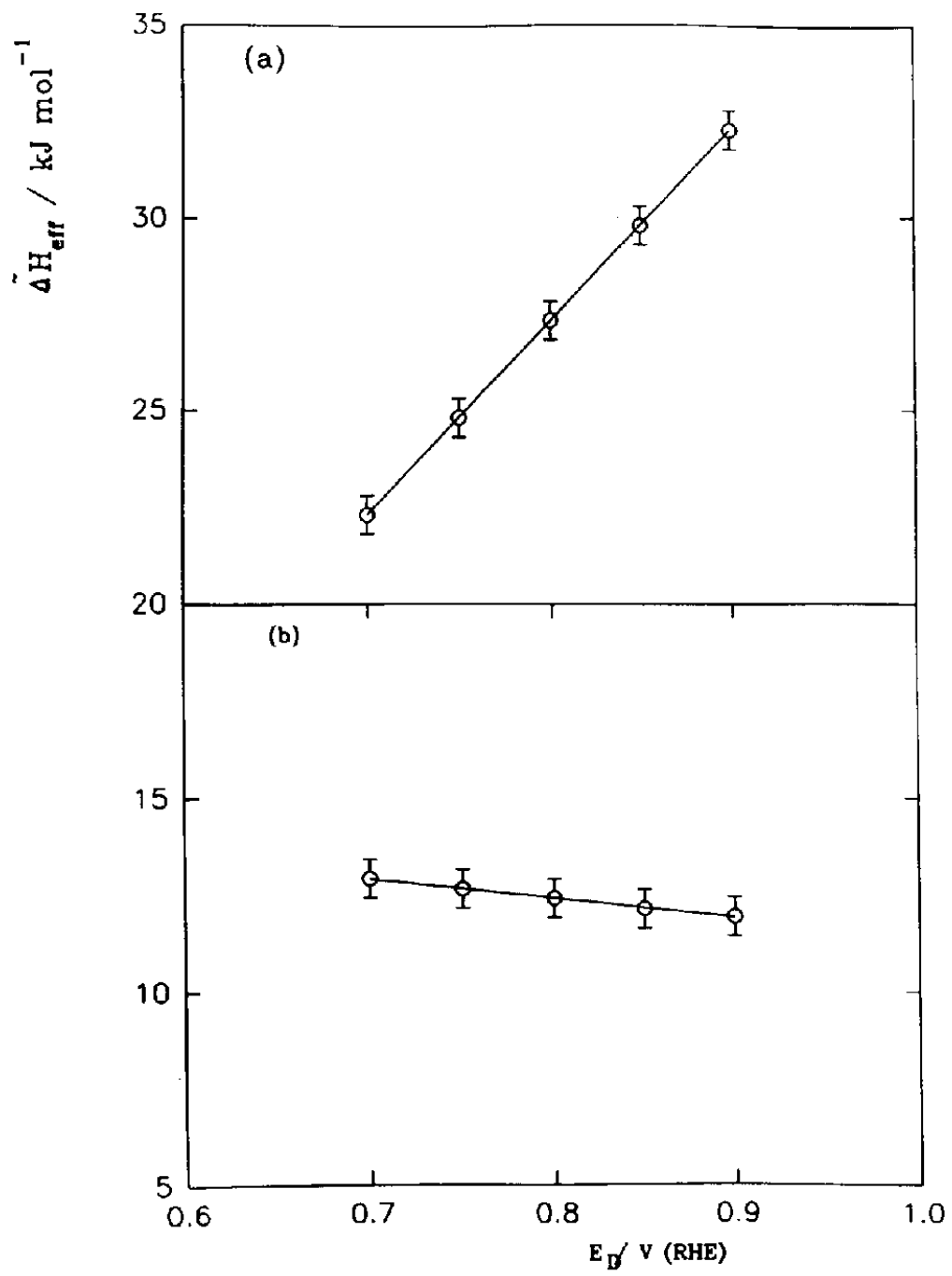

Fig. 3. Potential disc dependence of $\Delta \tilde{H}_{\text {eff }}^{*}$ for $\mathrm{OERR}$ in $\mathrm{O}_{2}$-saturated $1.0 \mathrm{M}$ aqueous $\mathrm{H}_{2} \mathrm{SO}_{4}$. (a) (111)type $\mathrm{Pt}$; (b) (100)-type Pt.

OERR on PC $P_{t}$ electrodes in dilute aqueous $\mathrm{H}_{2} \mathrm{SO}_{4}$ and $\mathrm{HClO}_{4}[11,12]$.

For (100)-type $\mathrm{Pt}$, an almost temperature invariant $\left(b_{\mathrm{T}}\right)_{\mathrm{HCD}}$ value is obtained, as earlier reported by Huang et al.[8] for the OERR on PC Pt in concentrated aqueous $\mathrm{H}_{3} \mathrm{PO}_{4}$ solutions. Temperature invariant Tafel slopes were also reported by $\mathrm{Zabu}$ sova et al.[29] for the HER on PC Pt in $\mathrm{H}_{2} \mathrm{SO}_{4}$ and $\mathrm{HCl}$ ethanolic solutions.

Values of $\left(j_{0}\right)_{\mathrm{LCD}}$ and $\left(j_{0}\right)_{\mathrm{HCD}}$ were also obtained by extrapolation of Tafel lines to the reversible $\mathrm{O}_{2}$ electrode potential. OERR kinetic parameters, derived under different experimental conditions, are assembled in Table 1.

\subsection{Arrhenius plots}

From Tafel plots obtained at different temperatures, electrochemical Arrhenius curves, $\ln j$ vs. $1 / T$, were made in the HCD range (Fig. 2), providing relationships between $j$ and temperature, at constant $E_{\mathrm{D}}[9]$. The effective electrochemical enthalpy of activation, $\Delta \tilde{H}_{\text {eff }}^{*}$, was obtained from the slope of these lines, and the logarithm of the pre-exponential factor in the rate equation, which contains the effective electrochemical entropy of activation, $\Delta \tilde{S}_{\text {eff }}^{*}$, was also derived from the intersection of Arrhenius straight lines with $(1 / T)=0$.

OERR Arrhenius behaviour considerably depends on the Pt surface texture. Thus, at the $\mathrm{O}_{2}$ electrode reversible potential, $\Delta \tilde{H}_{\mathrm{eff}}^{*}=48.8 \mathrm{~kJ} \mathrm{~mol}^{-1}$ for (111)type $\mathrm{Pt}$, whereas $\Delta \tilde{H}_{\mathrm{eff}}^{*}=10.6 \mathrm{~kJ} \mathrm{~mol}^{-1}$ for $(100)$ type Pt. It should be pointed out that the $\Delta \tilde{H}_{\text {eff }}^{*}$ value for (111)-type $P t$ is similar to that reported by Sepa $e t$ al. for the OERR on PC Pt in dilute aqueous $\mathrm{H}_{2} \mathrm{SO}_{4}$ and $\mathrm{HClO}_{4}[11]$.

The potential dependence of $\Delta \tilde{H}_{\text {eff }}^{*}$ is also different for both types of $\mathrm{Pt}$ electrodes (Fig. 3). For (111)type $\mathrm{Pt}, \Delta H_{\text {err }}^{*}$ increases as $E_{\mathrm{D}}$ approaches the $\mathrm{O}_{2}$ electrode reversible potential value, whereas for (100)-type $\mathrm{Pt}, \Delta \tilde{H}_{\text {eff }}^{*}$ appears to be practically constant at least within the experimental error (Fig. 3).

The pre-exponential factor, $(\ln j)_{1 / T=0}$, obtained from Arrhenius plots also shows a different potential behaviour for each type of facetted Pt electrodes 


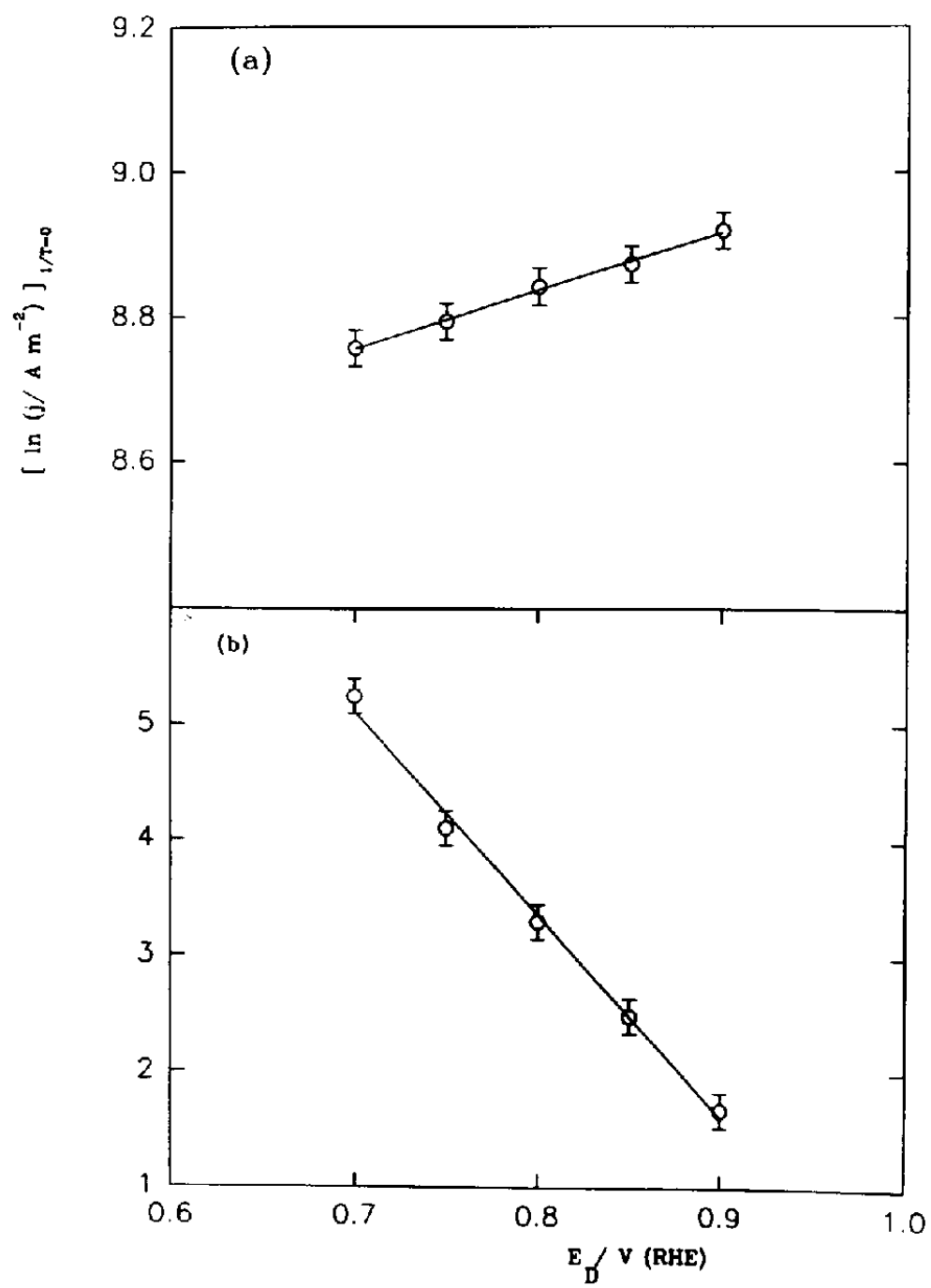

Fig. 4. Disc potential dependence of $(\ln j)_{1 / T=0}$ for OERR in $\mathrm{O}_{2}$-saturated $1.0 \mathrm{M}$ aqueous $\mathrm{H}_{2} \mathrm{SO}_{4}$. (a) (111)-type electrode; (b) (100)-type electrode.

(Fig. 4). For (100)-type Pt, $(\ln j)_{1 / T=0}$ changes with the applied potential, whereas this dependence becomes negligible for (111)-type Pt. For the latter, the assumption that potential effects on the activation entropy term are negligible could be justified.

\section{DISCUSSION}

\subsection{Some aspects of the $\mathrm{O}_{2}$ electrocatalysis on $\mathrm{Pt}$}

For the electrocatalytic reaction, such as the OERR, the height of the activation barrier depends on the extent of reactants and/or the adsorption of products, which changes their ground-states without any appreciable modification in the shape of the energy vs. reaction coordinate plot. Figure 5 shows the influence of the adsorption of OERR reactants and products through Morse curves. Considering the case of $\mathrm{O}_{2}$-reactant adsorbates without product adsorption, the activation barrier height, $\Delta \tilde{G}^{*}$, is defined by the intersection of curves (1) and (2).

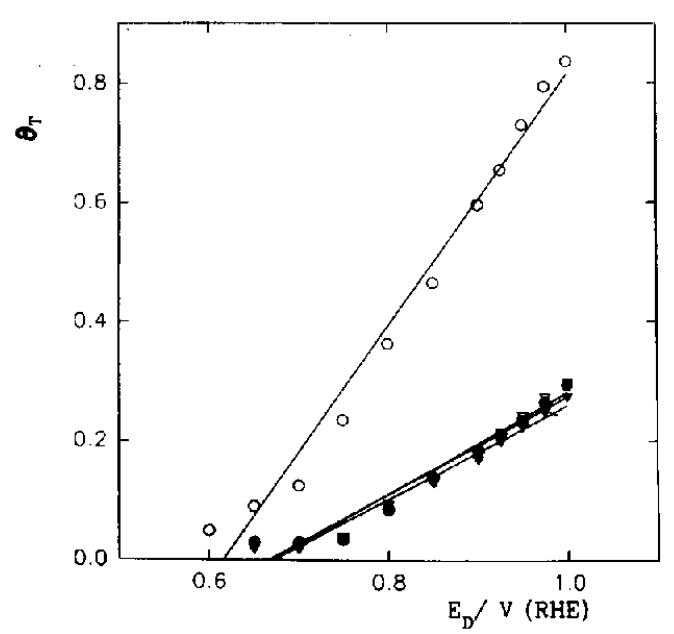

Fig. 5. Dependence of $\vartheta_{\mathrm{T}}$ on $E_{\mathrm{D}}$. (a) $\mathrm{O}_{2}$-saturated, $(\nabla)$ (111)-type $\mathrm{Pt},(\mathrm{O})$ (100)-type $\mathrm{Pt}$; (b) $\mathrm{O}_{2}$-free $1.0 \mathrm{M}$ aqueous $\mathrm{H}_{2} \mathrm{SO}_{4},(\nabla)(111)$-type $\mathrm{Pt},(\mathrm{O})(100)$-type Pt. $30^{\circ} \mathrm{C}$. 
Curve (1) represents the $\mathrm{O}_{2}$-reactant adsorbed intermediate Morse plot, and curve (2) stands for the product non-adsorbed intermediate. The stabilization of the intermediate product through adsorption, $\Delta \tilde{G}_{a d}$, decreases its ground-state energy. When the extent of the product adsorption is greater than that of the reactant, curve (2) changes to curve (3), defining a new free energy of activation, $\Delta \tilde{G}_{\text {eff }}^{*}$, determined by the intersection of curves (1) and (3). This $\Delta \hat{G}_{\text {eff }}^{*}$ value is lower than $\Delta \hat{G}^{*}$ and depends on the extent of stabilization of the intermediate product. Conversely, when the reactant adsorption energy is more important than that of the product, $\Delta \widetilde{G}_{\text {eff }}^{*}$ increases with respect to $\Delta \widetilde{G}^{*}$.

Since the OERR implies an initial $\mathrm{O}_{2}-\mathrm{Pt}$ interaction in the electrochemical interface, the knowledge of the $\mathrm{O}_{2}$ adsorbate configuration is required. According to gas-phase studies under ultra high vacuum (uhv) conditions[30,31], the molecular or dissociative $\mathrm{O}_{2}$ adsorption on $\mathrm{Pt}$ depends on the electronic characteristics of the surface[30 and refs therein]. Accordingly, the $\mathrm{O}_{2}$-adsorbate structure at the electrochemical interface in the HCD region would also depend on the surface texture of the electrode, leading to either side-on peroxide $\left(-\mathrm{O}_{2-}^{-}\right)$or $\mathrm{OH}-$ and O-type adsorbates, whether molecular or dissociative $\mathrm{O}_{2}$ adsorption takes place. From recent semi-empirical quantum chemistry calculations of $\mathrm{O}_{2}$ adsorption on Pt clusters, peroxo adsorbates were found to be the most likely intermediates on $\mathrm{Pt}(100)$ and $\operatorname{Pt}(111)$, this intermediate being less stable on the latter $[32,33]$. Otherwise, in the LCD region, ie at more positive potentials, end-on peroxide $\left(\mathrm{O}_{2} \mathrm{H}-\right)$ adsorbates are more likely, due to the decrease in $d$-orbital $\mathrm{Pt}$ vacancies at the onset of the $\mathrm{Pt}$ oxide layer formation.

An alternative three-step pathway for the OERR mechanism in aqueous acids, consistent with our experimental results for $\mathrm{Pt}$ facetted electrodes, is presented. The mechanism formally comprises an $\mathrm{O}_{2}$ adsorption equilibrium process, step (I), followed by a single electron transfer to the $\mathrm{O}_{2}$-adsorbate, step (II), which becomes the RDS in the HCD region, and the subsequent electrodecomposition of the peroxoadsorbate into several products, all of them collected in step (III).

$$
\begin{gathered}
\mathrm{O}_{2}+\mathrm{Pt} \Leftrightarrow\left[\left(\mathrm{O}_{2}\right) \mathrm{Pt}\right]_{\mathrm{ad}} \\
{\left[\left(\mathrm{O}_{2}\right) \mathrm{Pt}\right]_{\mathrm{ad}}+\mathrm{H}^{+}+\mathrm{e}^{-} \Rightarrow\left[\left(\mathrm{O}_{2} \mathrm{H}\right) \mathrm{Pt}\right]_{\mathrm{ad}}(\mathrm{RDS})} \\
{\left[\left(\mathrm{O}_{2} \mathrm{H}\right) \mathrm{Pt}\right]_{\mathrm{ad}}+\mathrm{H}^{+} \mathrm{e}^{-} \Rightarrow \text { products. }}
\end{gathered}
$$

Then, the overall rate of the OERR in the HCD region can be expressed in terms of the current density of step (II), $j_{\mathrm{n}}$, as:

$$
\begin{aligned}
& j_{\mathrm{n}}=\kappa F(k T / h) c_{\mathrm{H}+} \vartheta_{\mathrm{O}_{2}} \exp \left(-\Delta \tilde{G}^{*} / R T\right. \\
& \times \exp \left(\gamma \Delta \Delta \tilde{G}_{\mathrm{ad}} / R T\right)
\end{aligned}
$$

where $\kappa$ is the nuclear transmission coefficient for reactants, $c_{\mathbf{H}^{+}}$is the $\mathbf{H}^{+}$ion concentration in the bulk of the solution, $\vartheta_{\mathrm{O}_{2}}$ is the surface coverage by the $\mathrm{O}_{2}$-reactant adsorbates, $\Delta \widetilde{G}^{*}$ is the change in the electrochemical activation free energy, $\Delta \Delta \tilde{G}_{a d}$ stands for the difference in the electrochemical adsorption free energy between reactants and products, and $\gamma$ gives the fractional contribution of $\Delta \Delta \tilde{G}_{2 d}$ to the activation energy assisting the process in the forward direction.

The net change of the activation barrier height due to the adsorption of reactants and products can be considered in the expression of the current density through $\gamma \Delta \Delta \tilde{G}_{\text {ad }}$. In fact, $\gamma$ represents the fraction of the electrical potential drop at the electrode/solution interface, which affects the adsorbed species[34]. Furthermore, potential energy curves can be drawn as straight lines near the crossing point, so that $\gamma$ is nearly constant over the entire reaction coordinate. Changes in the activation barrier heights as a result of adsorption were firstly considered by Brönsted[35], later extended to electrochemical systems by Horiuti and Polanyi[36] and reexamined by Appleby[37]. From the above considerations, the effective activation energy for the OERR, $\Delta \tilde{G}_{\text {eff }}^{*}$, will include two different contributions, $i e \Delta \tilde{G}^{\#}$ and $\Delta \Delta \tilde{G}_{\mathrm{ad}}$.

Since adsorption changes the electrochemical activation energy, the knowledge of the degree of surface coverage by OERR intermediates as a function of potential is required for each facetted Pt surface. In this respect, $\vartheta_{T}$, the stationary degree of surface coverage by the total $\mathrm{O}$-containing adsorbates, was determined in $\mathrm{O}_{2}$-saturated $1.0 \mathrm{M}$ aqueous $\mathrm{H}_{2} \mathrm{SO}_{4}$ on (111)- and (100)-type Pt electrodes (Fig. 6). Thus, $\vartheta_{\mathrm{T}}$ in $\mathrm{O}_{2}$-saturated sulfuric solution on (100)-type $\mathrm{Pt}$ was always greater than that on (111)-type $\mathrm{Pt}$, ie $\vartheta_{\mathrm{T}}=0.52$ for $(100)$-type $\mathrm{Pt}$ and $\vartheta_{\mathrm{T}}=0.17$ for $(111)$ type $\mathrm{Pt}$ at $0.85 \mathrm{~V}$. However, the situation changes when the value of $\vartheta_{T}$ is determined in $\mathrm{O}_{2}$-free aqueous $\mathrm{H}_{2} \mathrm{SO}_{4}$ solutions, since it becomes almost the same, ie $\vartheta_{\mathrm{T}}=0.16$ at $0.85 \mathrm{~V}$, for both $\mathrm{Pt}$ facetted electrodes (Fig. 6).

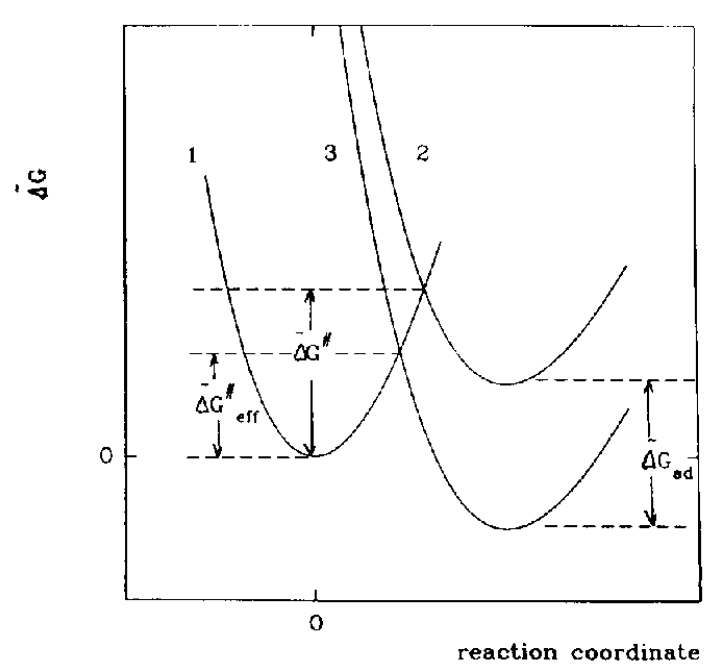

Fig. 6. Influence of adsorbed products involved in the OERR on the potential energy (Morse) curves. Curve (1) stands for the $\mathrm{O}_{2}$-reactant adsorbed intermediate. Curve (2) stands for non-adsorbed intermediates. Curve (3) stands for adsorbed intermediates. $\Delta \tilde{G}^{*}$ is defined at the intersection of curves (1) and (2); $\Delta \hat{G}_{\mathrm{ad}}$ stands for the decrease in the minimum energy ordinate from that of curve (2) to that of curve (3). $\Delta G_{\text {eff }}^{*}$ is defined at the intersection of curves (1) and (3). 
Since $\vartheta_{\mathrm{T}}$ in $\mathrm{O}_{2}$-saturated $1.0 \mathrm{M}$ aqueous $\mathrm{H}_{2} \mathrm{SO}_{4}$ can reach relatively high values, $\Delta \Delta \tilde{G}_{\text {ad }}$ must be considered as dependent on $\vartheta_{T}$

$$
\Delta \Delta \bar{G}_{\mathrm{ad}}=\Delta \Delta \bar{G}_{\mathrm{ad}, s_{\mathrm{T}}=0}+f\left(\vartheta_{\mathrm{T}}\right) .
$$

In our case, a Temkin-type isotherm can be considered for $f\left(\vartheta_{\mathrm{T}}\right)$, as a linear function of $\vartheta_{\mathrm{T}}$. Accordingly, the expression for $f\left(\vartheta_{\mathrm{T}}\right)$ becomes:

$$
f\left(\vartheta_{\mathrm{T}}\right)=r \vartheta_{\mathrm{T}},
$$

where $r=\left(\partial \Delta \Delta \tilde{G}_{\mathrm{ad}} / \partial \vartheta_{\mathrm{T}}\right)$ at constant temperature.

In both $P t$ facetted electrode surfaces, linear potential dependences of $\vartheta_{\mathrm{T}}$ were found, but with greater $\left(\partial \vartheta_{\mathrm{T}} / \partial E\right)$ values for (100)-type Pt (Fig. 6).

$$
\vartheta_{\mathrm{T}}=\vartheta_{\mathrm{E}=0}+K E,
$$

where $K=\left(\partial \vartheta_{\mathrm{T}} / \partial E\right)$ at constant temperature.

Since it was assumed that $\Delta \Delta \bar{G}_{\text {ad }}$ for the OERR intermediates depends on $\vartheta_{\mathrm{T}}, \Delta \Delta \tilde{G}_{\mathrm{ad}}$ results potential-dependent, and the following relationship can be established:

$$
\Delta \Delta \tilde{G}_{\mathrm{ad}}=\Delta \Delta G_{\mathrm{ad}, \vartheta_{\mathrm{T}}=0}+r \vartheta_{E=0}+r K E .
$$

On the other hand, from the proposed reaction scheme $\vartheta_{\mathrm{O}_{2}}$, the degree of surface coverage exclusively by $\mathrm{O}_{2}$-reactant adsorbed intermediates can be obtained, and substituting it in equation (1), the OERR current density results

$$
\begin{aligned}
& j_{\mathrm{II}}=\kappa F(k T / h) c_{\mathrm{H}^{+}} P_{\mathrm{O}_{2}}\left(1-\vartheta_{\mathrm{T}}\right) \\
& \times \exp \left[\left(\Delta \Delta G_{\mathrm{ad}, 9_{\mathrm{T}}=0}+r \vartheta_{E=0}+r K E\right) / R T\right] \\
& \times \exp \left(-\Delta \tilde{G}^{*} / R T\right) \exp \left(\gamma \Delta \Delta \tilde{G}_{\mathrm{ad}} / R T\right),
\end{aligned}
$$

where $P_{\mathrm{O}_{2}}$ is the $\mathrm{O}_{2}$ saturation pressure in the solution.

Equation (6) allows us to evaluate OERR kinetic parameters at different potentials and temperatures.

\subsection{The influence of the electrode potential on the OERR kinetics}

Let us consider the influence of the potential on the kinetics of the OERR through equation (6). A potential applied to the $\mathrm{Pt} /$ aqueous electrolyte interface implies a change in the Fermi level of PT electrons, reflected as a shift in $\Delta G^{*}$ through $\alpha F E, \alpha$ being the electrochemical transfer coefficient assisting the OERR in the forward direction. Earlier works[19 and refs therein] have shown that the electrode potential influence on the reaction rate does not always correspond to a temperature-independent $\alpha$ value.

The temperature dependence of $\alpha$ can be better considered as that derived from the potential dependences of both $\Delta \hat{H}^{*}$ and $\Delta \tilde{S}^{*}$, since the OERR occurs at an electrified metal/electrolyte interface. Then, considering that $\Delta \tilde{G}^{*}=\Delta \tilde{H}^{*}-T \Delta \tilde{S}^{*}, \alpha$ can be expressed as $\alpha_{H}-\alpha_{S} T[18,19]$, where $\alpha_{H}$ and $\alpha_{S}$ are defined as:

$$
\alpha_{H}=1 / F\left(\partial \Delta \tilde{H}^{*} / \partial E\right)_{\mathrm{T}}
$$

and

$$
\alpha_{S}=1 / F\left(\partial \Delta \tilde{S}^{*} / \partial E\right)_{\mathrm{T}}
$$

Equations (7a) and (7b) take into account the internal influence of the interfacial field on the metal and the external effect on the double-layer caused by the adsorbed species (compensation effect)[16].

On the other hand, it should be noted, that the physical origin of the temperature dependence of $\alpha$ is still far from being completely understood. According to Conway[19], it could be related to potential and temperature effects on solvent dipole orientations in the electrode interphase, although Bockris and Gochev[21] considered that the solvent orientation effect is too small to account for the observed experimental temperature dependence of $x$. Since the potential dependence of $\Delta \tilde{S}^{*}$ may be either positive or negative $[15,38]$, another theoretical explanation of the temperature dependence of $\alpha$, based upon nuclear tunnelling to the classical transfer $[39,40]$ was advanced, but these considerations only lead to small effects on the electrode reaction rate.

Furthermore, the possibility that $\Delta \widetilde{S}^{*}$ could reach a maximum, as the reaction coordinate goes from reactants to products, has already been considered[20]. In principle, a linear decrease in $\Delta \widetilde{S}^{*}$ with the reaction coordinate should be expected as both vibrational and translational energies of adsorbed products are probably lower than those of reactants, although obviously this situation largely depends on both the type of the adsorption isotherm and the extent of the own adsorption process.

In addition, it could be argued that as $\vartheta_{\mathrm{T}}$ increases, the values of $\Delta \Delta \tilde{S}_{\mathrm{ad}}$, the change of the electrochemical adsorption entropy between products and reactants, will also vary. This is only possible when the surface concentration of OERR intermediates is great, since lateral interactions, which are responsible for the existence of $r_{\mathrm{s}}$, are important only when $\vartheta_{\mathrm{T}} \Rightarrow 1$. In this case, it can be considered that $\Delta \Delta \widetilde{S}_{\mathrm{ad}}$ could vary according to:

$$
\Delta \Delta \tilde{S}_{\mathrm{ad}}=\Delta \Delta S_{\mathrm{ad}, g_{\mathrm{T}}=0}+r_{\mathrm{S}} \vartheta_{E=0}+r_{\mathrm{S}} K E
$$

where $r_{\mathrm{S}}=\left(\partial \Delta \Delta \boldsymbol{S}_{\mathrm{gd}} / \partial \vartheta_{\mathrm{T}}\right)_{\mathrm{E}}$ and $\Delta \Delta S_{\mathrm{ad}, \vartheta_{\mathrm{T}}=0}$ stands for the change of $\Delta \Delta S_{2 d}$ between reactants and products at $\vartheta_{\mathrm{T}}=0$. Under this assumption, and considering that $\Delta \Delta \tilde{G}_{\mathrm{ad}}=\Delta \Delta \tilde{H}_{\mathrm{ad}}-T \Delta \Delta \tilde{S}_{\mathrm{ad}}$ and $\Delta \tilde{G}^{*}=\Delta \tilde{H}^{*}$ $-T \Delta \tilde{S}^{*}$, their substitution in equation (6) leads to the following current density expression for the HCD region:

$$
\begin{aligned}
j_{\mathrm{II}}= & \kappa F(k T / h) c_{\mathrm{H}}+P_{\mathrm{O}_{2}}\left(1-\vartheta_{\mathrm{T}}\right) \exp \left(-\Delta H^{*} / R T\right) \\
& \times \exp \left(\Delta S^{*} / R\right) \\
& \times \exp \left[(1+\gamma) \Delta \Delta H_{2 \mathrm{~d}, s T=0} / R T\right] \\
& \times \exp \left[(1+\gamma) r_{\mathrm{H}} \vartheta_{E=0} / R T\right] \\
& \times \exp \left[(1+\gamma) r_{\mathrm{H}} K E / R T\right] \\
& \times \exp \left[-(1+\gamma) \Delta \Delta S_{\vartheta_{T}=0} / R T\right] \\
& \times \exp \left[-(1+\gamma) r_{\mathrm{S}} \vartheta_{E=0} / R T\right] \\
& \times \exp \left[-(1+\gamma) r_{\mathrm{S}} K E / R T\right] \\
& \times \exp \left[-\left(\alpha_{\mathrm{H}} F E / R T\right)\right] \exp \left(\alpha_{\mathrm{S}} F E / R T\right)
\end{aligned}
$$

The electrochemical activation parameters derived from Arrhenius plots correspond to the effective 
enthalpic and entropic barriers for the electron transfer at a given potential. Then the formal expressions for $\Delta \Delta \tilde{H}_{\text {eff }}$ and $\Delta \Delta \tilde{S}_{\text {eff }}$ can be derived from equation (9)

$$
\begin{array}{r}
\Delta \Delta \tilde{H}_{\text {eff }}=\Delta H^{*}-(1+\gamma) \Delta \Delta H_{\vartheta_{\mathrm{T}}=0}-(1+\gamma) r_{H} 9_{\mathrm{E}=0} \\
-\left[(1+\gamma) r_{H} K-\alpha_{H} F\right] E \\
\Delta \Delta \tilde{S}_{\text {eff }}=\Delta S^{*}-(1+\gamma) \Delta \Delta S_{\vartheta_{T}=0}-\alpha_{S} F E
\end{array}
$$

If one considers that $\left[\partial\left(1-\vartheta_{\mathrm{T}}\right) / \partial E\right] \ll$ $\left[\partial \exp \left(\vartheta_{\mathrm{T}}\right) / \partial E\right]$, the $\left(1-\vartheta_{\mathrm{T}}\right)$ term in equation (9) can be neglected. Moreover, $\Delta \Delta \tilde{S}_{\mathrm{ad}}$ can be considered to vary little with $\vartheta_{T}$, since in the HCD region it is lower than 0.6 . Then, a simpler equation describing the potential dependence of $j_{\mathrm{n}}$ can be obtained

$$
\begin{aligned}
j_{\mathrm{II}}=K \exp \left[-(1-\gamma) r_{\mathrm{H}} K E / R T\right] \\
\times \exp \left[-\alpha_{H} F E / R T\right] \exp \left[\alpha_{S} F E / R T\right]
\end{aligned}
$$

where $K$ contains all the electrode potentialindependent terms.

\subsection{The temperature-dependence of OERR Tafel slopes}

The influence of the surface texture on the kinetics and the mechanism of the OERR at Pt electrodes has been emphasized[6, 7, 41-43]. However, this influence does not reflect throughout $\left(b_{\mathrm{T}}\right)_{\mathrm{LCD}}$ except for $\left(b_{\mathrm{T}}\right)_{\mathrm{HCD}}$. Values of $\left(b_{\mathrm{T}}\right)_{\mathrm{HCD}}$ close to $-2.3(2 R T / F)$ were found (111)-type $\mathrm{Pt}$ and are often explained through a reaction scheme involving the first electron transfer as RDS, under Langmuirian adsorption conditions, for the intermediates[44, 45]. However, this mechanism cannot be applied to OERR results for (100)-type, since Tafel slopes of ca. 2.3(2.8RT/F) were found in the HCD region. Rotating ring-disc electrode ( $r r d e)$ data[7, 27] showed that an appreciable amount of $\mathrm{H}_{2} \mathrm{O}_{2}$ is formed on (100)-type $\mathrm{Pt}$ during the OERR $[7,27]$ whereas the formation of $\mathrm{H}_{2} \mathrm{O}_{2}$ on (111)-type $\mathrm{Pt}$ becomes negligible. Such high Tafel slopes were attributed to the influence of surface coverage by peroxide-adsorbates on the current density through $\Delta \Delta \bar{G}_{\mathrm{ad}}[7,37]$.

4.3.1. The (100)-type Pt electrodes. Let us examine our results for the OERR on (100)-type $\mathrm{Pt}$ in aqueous acid solutions. From Arrhenius plots, the potential dependence of $\Delta \tilde{H}_{\text {eff }}$ leads to $\left(\partial \Delta \tilde{H}_{\text {eff }} / \partial E\right)=-5.1 \mathrm{~kJ} \mathrm{~mol}^{-1}$ (Fig. 3). Taking into account equation (10), it follows that

$$
\begin{aligned}
\left(\partial \Delta \tilde{H}_{\mathrm{eff}} / \partial E\right)=\left[\alpha_{H} F-(1+\gamma) r_{H} K\right] & \\
& =-5.1 \mathrm{~kJ} \mathrm{~mol}^{-1} .
\end{aligned}
$$

On the other hand, since the electric dependence of $\Delta \Delta \widetilde{H}_{a d}$ can be expressed through $\mathrm{d}\left(\Delta \Delta \widetilde{H}_{\mathrm{ad}}\right)=$ $F \mathrm{~d} E$, and since $\Delta \Delta \tilde{H}_{\mathrm{ad}}$ also fits the expression $\mathrm{d}\left(\Delta \Delta \mathscr{H}_{\mathrm{ad}}\right)=r_{H} K \mathrm{~d} E$, it can be concluded that $r_{H} K=F$. Hence, considering equation (13), it results $\left[\alpha_{H}-(1+\gamma)\right]=-0.052$.

Furthermore, the slope of the $(\ln j)_{1 / T=0}$ vs. E plot (Fig. 4) is $\alpha_{S} F$, so, from the numerical values derived from Fig. 4 , the value $\alpha_{s}$ is obtained, namely, $\alpha_{s}=$ $-1.2 \times 10^{-3}$.

Finally, when all these figures are considered, it results $\left[\alpha_{H}-(1+\gamma) r_{H} K / F\right] \ll T \alpha_{S}$. Then, the expression for $\left(b_{\mathrm{T}}\right)_{\mathrm{HCD}}$ on (100)-type $\mathrm{Pt}$ can be obtained from equation (12)

$$
\begin{aligned}
&\left(b_{\mathrm{T}}\right)_{\mathrm{HCD}}=-\frac{2.3 R T}{\left[\alpha_{H}-T \alpha_{S}+(1-\gamma) r_{H} K / F\right] F} \\
& \cong \frac{2.3 R}{\alpha_{S} F} .
\end{aligned}
$$

Hence, for the OERR on (100)-type $P t$ in an aqueous environment, $\left(b_{\mathrm{T}}\right)_{\mathrm{HCD}}$ becomes temperature independent and equal to $-0.163 \mathrm{~V}$ decade $^{-1}$ value, ie a Tafel slope which agrees with experimental figures at all temperatures (Table 1).

4.3.2. The (111)-type Pt electrodes. For (111)-type $\mathrm{Pt}, \vartheta_{\mathrm{T}}<0.2$ in the HCD region, so that $\Delta \Delta \bar{G}_{\text {ad }}$ can be considered almost constant and equal to $\Delta \Delta G_{\mathrm{ad}, s_{\mathrm{T}}=0}$. Accordingly, the potential contribution of $\Delta \Delta G_{\mathrm{ad}}$ to the overall current density (equation 12) becomes negligible as it should be expected from a Langmuirian behaviour. In this case, the potentialdependence of $\Delta \tilde{H}_{\text {eff }}^{*}$ yields a slope equal to $\alpha_{H} F$. Taking into account the experimental $\left(\partial \Delta \widetilde{H}_{\text {eff }} / \partial E\right)$ value $\left(50 \mathrm{~kJ} \mathrm{~mol}^{-1}\right)$, the conventional $\alpha_{H}=0.5$ value is obtained. Otherwise, $(\ln j)_{1 / T=0}$ is almost potential-independent, so, it will lead to an almost negligible $\alpha_{S}$ value. In fact, from the slope of the $(\ln j)_{1 / T=0}$ vs. $E$ plot (Fig. 4) it results in $\alpha_{S} \sim 10^{-6}$.

Since $\alpha_{H}=0.5$ and $\left(\partial(\ln j)_{1 / T=0} / \partial E\right) \approx 0$, the $\left(b_{\mathrm{T}}\right)_{\mathrm{HCD}}$ for the OERR on (111)-type $\mathrm{Pt}$ can be written as follows

$$
\left(b_{\mathrm{T}}\right)_{\mathrm{HCD}}=-2.3 R T / \alpha_{H} F .
$$

This expression of $\left(b_{\mathrm{T}}\right)_{\mathrm{HCD}}$ becomes temperature dependent and it is consistent with $\left(b_{\mathrm{T}}\right)_{\mathrm{HCD}}=$ $-0.118 \mathrm{~V}$ decade $^{-1}$ at $T=298 \mathrm{~K}$, found experimentally. In this case, simplified classical electrode kinetics is applicable to the OERR on this type of Pt electrode.

The preceding discussion was mainly based on the assumptions that the temperature dependence of OERR kinetics is influenced by adsorption properties of intermediates and compensation effects. However, it should be expected that other effects, such as differences in the degree of anion adsorption, temperature dependences of interfacial solvent structure, coadsorption processes, non-adiabatic electron transitions, and proton tunnelling, could also be involved. Some of these questions were previously considered by Appleby[20] and Bockris and Gochev[21], but their potential dependence still remains rather ambiguous. Certainly, some extra considerations concerning the transmission coefficients of atoms and electrons could be made, ie the adiabaticity of the process. Actually, a general approach to the role of the electron in the transitionstate complex in electrocatalysis has still not been considered. Simplification of the classical electron transfer theory would, then, lead to erroneous results. Perhaps, further advances in the OERR mechanism could be made through the knowledge of the configuration of the activated complex formed on both $\mathrm{Pt}$ electrode surfaces. This goal can be approached by applying quantum chemistry calculations in relation to the OERR, as will be reported in a forthcoming publication[46]. 


\section{CONCLUSIONS}

(i) A reaction scheme was proposed to interpret the kinetic data on the temperature dependence of the OERR on Pt facetted electrodes in aqueous sulfuric acid solutions. The reaction scheme comprises a RDS involving adsorbed $\left[\left(\mathrm{O}_{2}\right) \mathrm{Pt}\right]_{\mathrm{ad}}$ and $\left[\left(\mathrm{O}_{2} \mathrm{H}\right) \mathrm{Pt}\right]_{\mathrm{ad}}$ species, the latter is the species more tightly bound to the surface. The difference in the adsorption process of these species decreases the activation energy barrier of the OERR.

(ii) A Temkin adsorption isotherm was considered for the OERR adsorbed intermediates. Greater $\vartheta_{\mathrm{T}}$ and $\left(\partial \vartheta_{\mathrm{T}} / \partial E\right)$ values for $(100)$-type $\mathrm{Pt}$ with respect to those for (111)-type $\mathrm{Pt}$, cause a larger potential dependence of the electrochemical adsorption free energy.

(iii) The influence of the electrode potential on the OERR was considered in both $\Delta \tilde{H}^{*}$ and $\Delta \tilde{S}^{*}$ leading to $\alpha=\alpha_{H}-\alpha_{S} T$. A temperature-dependent $\alpha$ value is responsible for the major potential dependence of $\Delta \tilde{S}^{*}$, for (100)-type Pt.

(iv) Tafel lines at HCDs on (111)-type Pt follow a conventional activated-controlled process with $\left(b_{\mathrm{T}}\right)_{\mathrm{HCD}}$ dependent on temperature, whereas Tafel lines on (100)-type $\mathrm{Pt}$ at HCDs exhibit a temperature independent $\left(b_{\mathrm{T}}\right)_{\mathrm{HCD}}$ value as a consequence of the greater potential dependence of both $\Delta \tilde{S}^{*}$ and $\Delta \Delta \tilde{G}_{\text {ad }}$

Acknowledgements-This work was financially supported by the Consejo Nacional de Investigaciones Científicas $y$ Técnicas (CONICET) of Argentina. C. F. Z thanks the Universidad de la Repúblic, Montevideo (Uruguay) and CONICET for the fellowship granted. A. M. C. L. belongs to the Researcher Career of the Comision de Investigaciones Cientificas de la Provincia de Buenos Aires (CIC).

\section{REFERENCES}

1. J. O'M. Bockris and S. Srinivasan, Fuel Cells: Their Electrochemistry, Chap. 9. McGraw-Hill, New York (1969)

2. E. B. Yeager, Electrochim. Acta 29, 1527 (1984).

3. A. J. Appleby, National Meeting of the Electrochem. Soc. Ext. Abst. p. 23 (1975).

4. A. Damjanovic and V. Brusic, Electrochim. Acta 12, 615 (1967).

5. A. J. Appleby, J. electrochem. Soc. 117, 641 (1970).

6. F. El Kadiri, R. Faure and R. Durand, J. electroanal. Chem. 301, 1 (1991).

7. C. F. Zinola, A. M. Castro Luna, W. E. Triaca and A. J. Arvia, J. appl. Electrochem. 24, 119 (1994).

8. J. C. Huang, R. K. Sen and E. B. Yeager, J. electrochem. Soc. 26, 786 (1988).

9. A. J. Appleby, J. electrochem. Soc. 117, 328 (1970).

10. S. J. Clouser, J. C. Huang and E. B. Yeager, J. appl. Electrochem. 23, 597 (1993).

11. D. B. Sepa, M. V. Vojnovic, Lj. M. Vracar and A. Damjanovic, Electrochim. Acta 31, 91 and 97 (1986).

12. D. B. Sepa, M. V. Vojnovic, Lj. M. Vracar and A. Damjanovic, Electrochim. Acta 31, 1105 (1986).
13. A. Damjanovic and D. B. Sepa, Electrochim. Acta 35, $1157(1990)$

14. B. E. Conway and D. J. McKinnon, J. electrochem. Soc. 116, 1665 (1969).

15. B. E. Conway, D. J. McKinnon and B. V. Tilak, Trans. Faraday Soc. 73, 1203 (1969).

16. B. E. Conway, D. P. Wilkinson and D. F. Tessier, Ber. Bunsenges. phys. Chem. 91,484 (1987)

17. A. Damjanovic, B. E. Conway and D. B. Sepa, Ber. Bunsenges. phys. Chem. 93, 510 (1989).

18. B. E. Conway and D. P. Wilkinson, J. electroanal. Chem. 214, 633 (1986).

19. B. E. Conway, in Modern Aspects of Electrochemistry (Edited by B. E. Conway, J. O'M. Bockris and R. E. White), Vol. 16, Chap. 2. Plenum Press, New York (1985).

20. A. J. Appleby, in Proceedings of the Symposium on Electrocatalysis (Edited by M. W. Breiter), p. 78. The Electrochemical Society, Princeton, New Jersey (1974).

21. J. O'M. Bockris and A. Gochev, J. electroanal. Chem. 214, 655 (1986).

22. W. E. Triaca, T. Kessler, J. C. Canullo and A. J. Arvia, J. electrochem. Soc. 134, 1165 (1987).

23. H. Angerstein-Kozlowska, in $A$ Comprehensive Treatise of Electrochemistry (Edited by J. O'M. Bockris, E. B. Yeager, B. E. Conway and S. Sarangapani), Vol. 9, Chap. 2, p. 15. Plenum Press, New York, London (1984).

24. J. N. Agar, Discuss. Faraday Soc. 1, 81 (1947).

25. M. J. Weaver, J. phys. Chem. 83, 1748 (1979).

26. G. Brauer, Handbuch der Praeparativen Anorganischen Chemie, Part I, p. 304. Springer-Verlag, Stuttgart (1960).

27. C. F. Zinola, A. M. Castro Luna, W. E. Triaca and A. J. Arvia, Electrochim. Acta, submitted.

28. H. Angerstein-Kozlowska, B. E. Conway and W. B. A. Sharp, J. electroanal. Chem. 43, 9 (1973).

29. S. E. Zabusova, L. B. Kriksunov and V. M. Tsionskii, Elektrokhimiya 28, 456 (1992).

30. B. Hellsing, Surf. Sci. 282, 216 (1993).

31. X-C. Guo, J. M. Bradley, A. Hopkinson and D. A. King, Surf. Sci. 292, L786 (1993).

32. L. Pauling, Nature 203, 183 (1964).

33. G. A. Benesh and L. S. G. Liyanage, Surf. Sci. 261, 207 (1992).

34. D. S. Gnanamuthu and J. V. Petrocelli, J. electrochem. Soc. 114, 1036 (1967).

35. J. N. Brönsted, Chem. Rev. 5, 231 (1928).

36. J. Horiuti and M. Polanyi, Acta Physicochim. (URSS) 2, 505 (1935).

37. A. J. Appleby, in A Comprehensive Treatise of Electrochemistry (Edited by B. E. Conway, J. O'M. Bockris, E. Yeager, S. U. M. Khan and R. White), Vol. 7, Chap. 4, p. 173. Plenum Press, New York (1983).

38. U. Frese and U. Stimming, J. electroanal. Chem. 198, $409(1986)$

39. A. M. Kuznetsov, J. electroanal. Chem. 159, 241 (1983).

40. J. Ulstrup, Electrochim. Acta 29, 1377 (1984).

41. P. N. Ross, J. electrochem. Soc. 126, 78 (1979)

42. P. Stonehart and P. N. Ross, Catal. Rev. 12, 1 (1975).

43. L. J. Bregoli, Electrochim. Acta 23, 489 (1978).

44. A. J. Appleby, J. electrochem. Soc. 117, 328 (1970).

45. A. J. Appleby, in Modern Aspects of Electrochemistry (Edited by B. E. Conway and J. O'M. Bockris), Vol. 9, p. 369. Plenum Press, New York (1974).

46. C. F. Zinola, G. L. Estiú, E. A. Castro and A. J. Arvia, in preparation. 